\title{
UNIVERSALIZAÇÃO DE SERVIÇOS PÚBLICOS E COMPETIÇÃO O CASO DA DISTRIBUIÇÃO DE GÁS NATURAL
}

\author{
Floriano DE AZEVEDo MARQUES NETO*
}

Um dos temas mais relevantes para o direito público atual talvez seja a interface entre a atuação dos órgãos reguladores setoriais (ANATEL, ANEEL, ANP etc.) e os órgãos de defesa da concorrência (SDE, SAE e CADE), especialmente se evoluir a idéia de criação de uma agência de defesa da concorrência.

Uma manifestação recente desta complexa relação foi vivenciada recentemente na questão dos serviços de distribuição de gás canalizado.

Em análise das operações de privatização no setor, a SDE emitiu parecer, por intermédio do Departamento de Proteção e Defesa Econômica, em que são formuladas algumas recomendações que, no seu entender, deveriam ser adotadas com vistas a regularizar a operação. A principal delas apontaria para a adoção de providências voltadas a compelir, os atuais controladores das concessionárias a efetivar a separação jurídica entre as atividades de distribuição e comercialização (com a criação de duas empresas distintas, uma para cada propósito específico).

Ademais, recomenda o sobredito parecer que o contrato de concessão seja alterado de modo a permitir a aquisição, pelos grandes consumidores, de gás canalizado diretamente do city-gate ou do produtor, sempre que a configuração de rede assim o permita. Para tanto, recomendam i) a supressão do pagamento do by pass para os grandes consumidores; ii) definição mais racional do conceito de atividade de distribuição.

Por fim, entendendo que as medidas adotadas são insuficientes para ensejar a adequada competição no setor, sugere que i) as autorizações do funcionamento de usinas termoelétricas a gás natural sejam submetidas ao sistema de defesa da concorrência; e que ii) seja recomendado à ANELL um monitoramento constante das "empresas verticalizadas" com vistas a evitar práticas discriminatórias. O parecer não esclarece, neste ponto, se tal monitoramento seria diverso daquele já por lei exigido dos órgãos reguladores e se tal recomendação é extensiva também à ANP,

* Advogado. Doutor em Direito Público pela Universidade de São Paulo. Professor da Pontifícia Universidade Católica de São Paulo.

R. Dir. Adm.,

Rio de Janeiro, 223: 133-152, jan./mar. 2001 
haja vista que a verificalização apontada não se cinge apenas ao segmento de energia elétrica.

Preliminar exame da matéria indica tratar-se de discussão que envolve, pelo prisma do direito econômico, tema bastante complexo, em torno do qual muito se tem escrito no direito comparado, mas que não se encontra, ainda, suficientemente estudado no direito brasileiro. É que os processos de desestatização da exploração de utilidades públicas (termo genérico de que nos utilizamos para designar não só a prestação de serviços essenciais, como também a exploração de bens públicos e das assim chamadas essencial facilities ${ }^{l}$ ) ainda são recentes entre nós, mais até que no direito europeu.

No bojo dos processos de reestruturação do Estado (privatização, nova regulação estatal etc) surge a necessidade de novos enfoques na exploração de atividades econômicas antes nonopolizadas pelo poder público. Exemplo disso é o foco que o direito do consumidor e o direito econômico passam a dar sobre a prestação de serviços públicos. Questões que antes eram analisadas predominantemente sobre o estrito campo do direito administrativo passam agora a ser vistas também sobre o prisma do direito da concorrência. É o que ocorre com o assunto ora em análise.

$\mathrm{O}$ fato é que, fora do direito anglo-saxão (no qual não só as categorias do direito econômico encontram-se mais desenvolvidas, como também a exploração de public utilities já de há muito envolve a atuação de atores privados), a literatura jurídica acerca das questões trazidas é bastante recente. Mesmo no direito continental europeu não se pode dizer que exista uma doutrina sedimentada acerca de temas como monopólios de redes de serviços públicos, concentração vertical na exploração de atividades essenciais, introdução da competição em setores desestatizados. No caso específico do segmento de gás, a questão assume características ainda mais peculiares.

Digo isto até para justificar, no presente trabalho, uma eventual escassez de colações doutrinárias ou mesmo eventual empréstimo de reflexões desenvolvidas para setores congêneres (elétrico, telecomunicações ou ferrovias) que, pela semelhança, bem podem ser aproveitados nos raciocínios que se impõe desenvolver.

No mais, quando que nos debruçamos sobre temas novos ou no mínimo controvertidos, é sempre bom fazer a ressalva de que se está construindo um arcabouço teórico, para nós novo, a partir de dados da realidade econômica e jurídica pouco consolidados. E quem se dedica a esta tarefa sempre deve se despir de seus preconceitos, resistir à análise que se mostrar mais óbvia e tentar buscar a totalidade dos aspectos envolvidos, tentando, se possível, apreendendo o núcleo do que se discute.

A ressalva não deve ser tomada como crítica, ainda que indireta, ao bem lançado parecer da Secretaria de Direito Econômico que pauta as questões motivadoras deste estudo. Muito ao contrário, aquele trabalho se apresenta como indubitável resultado de uma reflexão detida e séria. Porém, creio haver aspectos outros do enfoque jurídico que merecem ser nuançados de modo a permitir mais ampla e descortinada análise,

1 Sobre a assim chamada "essencial facilities doctrine" ver o interessante estudo de Sally Van SICLEN "The Essential Facilities Concept", In OCDE/GD(96)113, Paris, 1996. 
agora a cargo do Conselho Administrativo de Defesa Econômica - CADE. É o que tentarei fazer doravante.

Já pude asseverar, em estudo anterior ${ }^{2}$, algumas notas sobre o monopólio de atividade econômica, em especial no caso de serviços públicos.

A transição de qualquer monopólio de atividade econômica para um regime de competição nunca será desvestida de complexidade. O rompimento do regime de monopólio, exclusividade ou privilégio, traz, necessariamente, duas ordens de desafios. Primeiro, descontaminar a cadeia produtiva da atividade econômica para tornar efetiva a competição. Segundo, dotar o segmento específico de mecanismos regulatórios aptos a permitir que, inobstante o regime de competição, seja assegurada que a atividade siga sendo oferecida aos consumidores ou usuários. Ou seja, a superação do monopólio sempre envolverá uma forte calibração entre medidas pró competição e medidas de preservação da estrutura de produção anterior, de modo a, no mínimo, não comprometer sua existência ou não comprometer sua eficiência econômica, razão em última instância da regulação estatal sobre atividades econômicas ${ }^{3}$.

Para os economistas, isso se deve ao fato de que, nas hipóteses de "monopólios naturais ${ }^{4}$, muita vez a simples introdução da competição, ao contrário de significar um incremento de eficiência no jogo econômico, serve para reduzi-la. Como ensinam POSSAS, PONDE e FAGUNDES, a introdução da competição nem sempre acarreta o aumento de eficiência: "Os casos típicos, muito tratados em economia industrial, sāo os chamados "monopólios (ou oligopólios) naturais", ..., qualquer tentativa de ampliar o número de produtores na indústria, de modo a estimular a concorrência, acarreta a presença de uma ou mais plantas de escala subótima, e, portanto, custos médios mais elevados que o mesmo nível de produção realizado pela oferta existente (monopolista ou oligopolista). Para esses casos, incluídos entre as convencionalmente chamadas "falhas de mercado", aceita-se de forma generalizada, mesmo nas abordagens ortodoxas, a regulação pública do mercado, de forma a impedir a prática de preços monopolísticos, mantendo-os próximos do nível de custos médios, entre outros objetivos regulatórios. Em outra palavras, abre-se mão, em nome da eficiência econômica - no caso, expressa em custos e preços mais baixos - , de uma estrutura de mercado mais competitiva, isto é, capaz de maior grau de concorrência". 5

Mais complexa ainda se torna essa transição quando estamos diante do rompimento de monopólio sobre atividades econômicas dotadas de essencialidade e im-

2 Ver meu "Reestruturação do Setor Postal Brasileiro", in Revista Trimestral de Direito Público, Malheiros Editores, Vol. 19, 1997, p. 149 e ss.

3 Cf. Mario Luiz POSSAS; João Luiz PONDE e Jorge FAGUNDES, "Regulação da Concorrência nos Setores de Infra-Estrutura no Brasil: Elementos para um Quadro Conceitual”, In "Infra-Estrutura - perspectivas e reorganização", Fernando REZENDE e Tomás Bruginski de PAULA (coordenadores), Brasilia, IPEA, 1997.

4 Segundo os economistas, aquele que ocorre quando o número de empresas que minimiza o custo total da indústria for igual a um (Cf. W.W. SHARKEY, "The Theory of Natural Monopoly", Cambrige University Press, 1989). Na síntese de Janusz A. ORDOVER e Russell W. PITTMAN.” 5 op. cit., p. 86. 
prescindibilidade para a coletividade. Ou seja, quando a transição do monopólio à competição envolve utilidades públicas cuja fruição se entende essencial para a sociedade - impondo, pois, que o poder público assuma a obrigação de assegurar sua permanente disponibilização em condições de plena acessibilidade a toda a gente - surgem outros objetivos regulatórios. É que a introdução da competição, se não observar mecanismos de gradação e transição, traz o risco de comprometimento do próprio caráter público da utilidade. É dizer, pode pôr em risco ou a perenidade da disponibilização desta utilidade ou então comprometer aspectos da política pública para o setor específico (por exemplo, ampliação da base de indivíduos com acesso à fruição de tal atividade).

Ana Maria NUSDEO sintetiza os desafios dessa transição de forma tão invulgarmente feliz que faço minhas suas assertivas. Diz a jovem professora que "detectada a possibilidade de funcionamento de um dado setor em regime de concorrência pelos reguladores é necessária a organização de uma transição da regulação para a concorrência, bem como a definição de quais segmentos dentro de uma cadeia produtiva têm condições de ser desregulamentados." 6 .

Logo na seqüência, vai deixar assentado que "em geral, não se passa diretamente de uma política de regulação à liberalização total das atividades. Ao contrário, a desregulação, por diversas razões, costuma ser parcial. Isso se explica por diferentes razões econômicas ou políticas. As primeiras têm a ver com a incapacidade de certas fases das atividades antes monopolizadas de funcionar em concorrência. As primeira têm a ver com a incapacidade de certas fases das atividades antes monopolizadas de funcionar em concorrência. As últimas, por sua vez, estão relacionadas à alta relevância social das atividades envolvidas, que são estratégicas para o país elou serviços públicos cuja prestação deve seguir objetivos como o da universalização do acesso. Além disso, princípios próprios da prestação dos serviços públicos, como o da continuidade, não permitem oscilações na oferta e no preço ao consumidor, presentes com certa freqüência no regime de mercado. A propósito, deve ser lembrado que a implantação da concorrência como política para aumentar a eficiência, o investimento e a modernização não é a única finalidade da nova regulação dos setores envolvidos."

Para os economistas, a transição da situação de monopólio para uma situação de plena competição determina a permanência de níveis elevados de regulação. Por exemplo, na fixação de preços, remanescendo critérios de limitação tarifária. Assumindo como pressuposto que, num regime de ampla competição os preços, devam ser livremente fixados a partir das condicionantes de mercado, a permanência de forte regulação estatal se justificaria para corrigir as distorções potencialmente geradas pela situação dominante do agente até então monopolista.

Porém, no âmbito jurídico (mais próximo às razões políticas aludidas na transcrição retro) o motivo da permanência da regulação é de outra ordem. Não se destina exclusivamente a corrigir imperfeições do jogo econômico. Alvitra, isto sim, assegurar, a um só tempo, i) que a atividade desmonopolizada siga sendo oferecida à

6 Ver Ana Maria NUSDEO. "Agências Reguladores e Concorrência", In Carlos Ari SUNDFELD (coordendor), "Direito Administrativo Econômico", São Paulo, Malheiros, 2000, pp. 161 e 162. 
fruição da coletividade; e ii) que sua oferta seja generalizada e ampliada, ensejando que ela seja disponibilizada a uma parcela crescente da sociedade.

Para atingir estes objetivos, a regulação estatal sobre o setor antes monopolizado, no mais das vezes, não vai corresponder apenas à permanência residual de alguma regulação a corrigir imperfeições da concorrência em face do "monopólio natural". $\mathrm{Na}$ verdade, diante de atividades econômicas revestidas de caráter de essencialidade (mormente em se tratando de serviços públicos), a introdução da competição enseja um forte aumento da regulação.

Haverá situações em que esse aumento de regulação não visará o aumento de competição e sim a preservação de um plexo mínimo de condições apto a assegurar que o agente antes monopolista tenha condições de implantar metas de ampliação de redes, de universalização do serviço ou mesmo possa fazer investimentos que, em situações de ampla e franca competição, não se mostrariam viáveis (não só à luz de critérios lastreados em custo de oportunidade, mas também por moderadas taxas de retorno).

É que quando tratamos de utilidades públicas, a regulação econômica não pode se pautar apenas pelo prisma da competição. Os interesses da sociedade (os móveis da regulação estatal) enredados nessa atividade não são exclusivamente traduzidos por critérios de eficiência econômica tais como redução de custos e livre opção pelos usuários. Há toda uma gama de interesses de universalização e de perenidade na fruição destes serviços (porquanto se considere ser relevante para a coletividade que, como meta, todos os indivíduos possam se servir dessa utilidade) que justificam a preterição, ao menos transitória, de um regime de competição plena o qual tende a beneficiar sempre a parcela dos consumidores efetivos, em detrimento dos consumidores potenciais do serviço ${ }^{7}$.

7 Anteriormente explicitei essa dicotomia entre duas categorias de consumidores de uma dada utilidade pública da seguinte forma: "Cabe, aqui, estabelecer uma distinção extremamente relevante (ainda que pouco difundida) entre duas classes de consumidores que, de nossa parte, vislumbramos quando a utilidade de consumo fruível é um serviço essencial. Existe, de um lado, o consumidor efetivo do serviço, ou seja, aquele que tem acesso à utilidade pública e que se equipara à definição tradicional de consumidor. Os direitos deste consumidor são os clássicos direitos inerentes à relação de consumo, tal como a qualidade do serviço, a responsabilidade do fornecedor ou a justeza do preço, traduzida, aqui, em modicidade tarifária. Porém, em sede de serviços essenciais, há uma outra categoria de consumidor que podemos divisar. Trata-se do "consumidor potencial" da utilidade pública, aquele que, por razões econômicas, geográficas ou sociais não tem acesso ao serviço essencial, em que pese este ser, por definição, fruível por todo e qualquer um. No caso do consumidor excluído da fruição do serviço (que sendo essencial devem ser estendido a todos, pois que o caracteriza o traço da universalização) o principal direito a ser pelejado é o acesso ao serviço. Somente após dele dispor é que passarão a integrar sua pauta de interesse a qualidade ou os custos. A distinção entre estas duas categorias coloca-se extremamente relevante na discussão em torno da noção de "preço justo" pelo serviço (modicidade tarifária). Quando a expansão da rede de suporte à prestação de um serviço essencial é financiada internamente pelos próprios recursos gerados com a prestação (sem investimentos externos, sem subsídios estatais) postular uma tarifa módica pode significar impedir a expansão do número de indivíduos com acesso ao serviço, pois que significa a redução da capacidade de investimento do prestador. Neste sentido, pode-se ter uma oposição de interesse entre os consumidores efetivos e os consumidores potenciais. E o risco aqui é que esta 
Como ensina Carlos Ari SUNDFELD ${ }^{8}$, "nos serviços estatais há ainda outra questão vital: a dos usuários e dos excluidos. (...) dai essa fundamental missão das agências que cuidam dos serviços com milhões de usuários: proteger os consumidores. Todavia, especialmente no Brasil, os "sem serviço" ainda são o nó principal: há milhões de pessoas sem telefone, energia ou saneamento. Universalizar serviços básicos continua sendo um de nossos maiores desafios. Por isso, é preciso impor metas de expansão às prestadoras, no interesse dos excluídos, além de controlar a qualidade e as cobranças, no interesse do consumidor".

Se bem é verdade que a propriedade da rede, necessária à prestação de uma dada utilidade pública, coloca seu titular numa posição dominante que, se não for fragmentada por medidas regulatórias, inviabiliza a competição e enseja mesmo a violação da ordem econômica, menos verdadeiro também não é que o caráter essencial de que se reveste a exploração dessa utilidade pode exigir a imposição, a esse agente dominante, de ônus de ampliação, abertura e aperfeiçoamento dessa rede. $O$ que favorecerá não só a competição, mas, digamos, a própria democratização da fruiçãa da public utulity.

A imposição destes ônus, há que se convir, não poderá, contudo, ser efetivada sem que se reserve, durante um período, algumas prerrogativas para o agente dominante. Nem admitirá a introdução de um sistema competitivo que permita aos entrantes abocanhar a parcela rentável do mercado, legando a parcela dos hiposuficientes para o dominante. Neste contexto, a repartição entre ônus e bônus revela-se como empreitada a demandar engenho e arte do regulador. É o que pretendo abordar no tópico seguinte.

E patente a dificuldade de uma regulação estatal que encontre o ponto arquimediano, que viabilize uma ampla competição numa atividade, sem comprometer o atingimento de metas de universalização e continuidade. A dosimetria da competição ou, se quisermos, duração do período de transição acima referido é talvez o maior desafio regulatório para os setores que saem da situação do monopólio.

Constitui pressuposto, quase acaciano, de um serviço essencial que sua fruição por todos é tal que a própria coletividade assume o encargo de assegurar o seu provimento universal e contínuo. É certo que, a partir de algumas base de razoabilidade, a eleição de uma ou outra atividade como essencial sempre dependerá de uma opção política travada no âmbito do núcleo estratégico estatal. Mediante pautas normativas, $O$ Estado seleciona atividades para com as quais, dada a sua relevância social, assume a obrigação de garantir a permanente disponibilização (continuidade) e a ampliação do acesso dos cidadãos à sua fruição (universalização). Para tanto estas pautas normativas fazem recair sobre esta exploração o regime de direito público, apto a da conformação jurídica a estes dois vetores ${ }^{9}$.

oposição seja, desafortunadamente, arbitrada em favor dos primeiros, via de regra mais articulados e mobilizados." (CF, meu "A nova regulação estatal e as agências independentes", In "Direito Administrativo Econômico", cit., p. 86).

8 Carlos Ari SUNDFELD, "Introdução às Agências Reguladoras", cit., p. 34.

9 Para uma visão da mais hodierna formulação em torno do conceito de serviço público ver, por todos, Ferando Herren AGUILlAR, "Controle Social de Serviços Públicos", São Paulo, Max Limonad. 1999. 
É certo que a continuidade e a universalização têm custos. Descartando a hipótese (de todo inviável, além de irrita ao Direito) de carregar todos esses ônus sobre um só particular, tais custos deve ser absorvidos pela coletividade. ${ }^{10}$

Uma alternativa é a assunção dos ônus deste financiamento pela coletividade como um todo, mediante a transferência de recursos oriundos de fontes tributárias para cobrir o déficit gerado pela parcela não amortizável dos investimentos demandados pela universalização e continuidade.

Outra é carrear, total ou parcialmente, estes ônus para o próprio conjunto de indivíduos que, possuindo capacidade econômica, já usufruem desta utilidade. Em que pese a crítica feita pelos economistas aos mecanismos de subsídio cruzado, esta segunda alternativa se mostra bastante adequada em sede de algumas atividades essenciais, mormente aquelas em que o vulto do investimento necessário torna-se inviável em face de escassez de fontes tributárias a fazer-lhe frente ${ }^{11}$. Isso, bem entendido, desde que no sentido da atividade competitiva para a atividade regulada, de modo a financiar parte dos ônus regulatórios ${ }^{12}$.

10 Nesse sentido: "Hemos dicho también que dicha tasa de transición debe ser soportada por todos los consumidores sin discriminación (non bypassable levy), por los clientes elegibles y or los cautivos" Gaspar Ariño Ortiz Francisco Velasco "Los Costes de Transicion a la Competencia: Perspectiva Juridica", in Competencia y Setor Eletrico: Un nuevo Regimen Juridico, Madrid, Ed. Civitas, 1998, cit. p. 191.

11 Pertinente a análise desenvolvida por Luiza Rangel de MORAIS: "Dentro dessa premissa básica, de desenvolvimento auto-sustentado, a estrutura tarifária deve ser concebida com vistas à definiçāo de modelos para cada setor específico, de forma a estabelecer um ritmo para que os programas de investimentos, ampliação e modernização acompanhe, ofluxo das receitas, adotando a fórmula de subsídios apenas excepcionalmente. Para que tal modelagem seja implantada é necessário dimensionar, com boa margem de acerto, o saldo financeiro que o setor pode gerar ao longo dos anos de vigência de contrato de concessão, efeito que poderá ser conseguido através da fixação de parâmetros e prioridades para os investimentos pela concessionária, de acordo com as metas fixadas para o setor." (Cf. "A Reestruturação dos Setores de Infra-Estrutura e a Definição dos Marcos Regulatórios", In Fernando REZENDE e Tomás Bruginski de PAULA (coordenadores); "Infra-Estrutura - perspectivas e reorganização", cit., p. 41).

12 Neste sentido calha à perfeição o ensinamento de Willian J. Baumol, segundo quem "contrariamente a quanto ci si potrebbe aspettare normalmente, um tale assetto dei prezzi rende possible la concorrenza per tutti $i$ beni finali prodotti dal proprietario dell'essential facility, mantendo contemporaneamente $i$ sussidi incrociati ai prezzi di ciascuno di essi. Pertanto, questi prezi consentono al regolamentadore di ottenere entrambi i risoltati. Da um lato, essi consentono alla concorrenza si sopravvivere e addritura di propagarsi ad ogni settore del mercato. Dall'altro lato, essi ammettono la presenza di quei sussidi incrociati cosi tipicamente sostenuti dall'autorità. poiché. Per la ragioni esposte in precedenza, vengono reputati di interesse colletivo o preché diretamente indotti da pressioni politiche, L'autorità di regolazione può infatti a vlote decidere di tutelare, com sussidi inctrociati, agricoltori isolati e in difficoltà appure altri settori produttivi la cui assistenza risulterebbe troppo dispendiosa. Oppure, il regolamentatore può richieder che i prezi privilegino le famiglie piuttosto che le utenze commerciali, a causa dei benefici indiretti che alle imprese deriverebbero da um aumento del numero di consumatori finali. Più brevemente, l'autorità può promuvere il servizio universale, tramite l'introduzione di sussidi incrociati senza che questo ordine delel cose venga minascciato dalle tenzione di um regime concorrenziale. $\mathrm{CF}$. "A Ciascuno 
Já deixei consignado que o fato de uma dada atividade ser considerada essencial para a coletividade e, portanto, ser prestada em regime público (ou seja, sua eleição como serviço público) não pode mais significar que tal atividade deve er explorada em regime de monopólio ou de privilégio ${ }^{13}$. Daí concordar que se estabeleça a competição mesmo nestes setores. Tal não pode, contudo, ser feito de inopino, com açodamento. A admissão da competição nestas atividades (até mesmo pelo convívio de agentes explorando a data utilidade concomitantemente em regime público e privado) não pode pôr em risco nem a prestação em regime público, nem o atingimento de metas de universalização.

Para se chegar próximo ao equilibrio ora buscado, evitando que um vetor (competição) inviabilize os outros (universalização e continuidade) entendo que se deva adotar a pauta de identificação do consumidor beneficiário. Deveras, é a identificação do consumidor (usuário) destinatário do benefício gerado pela maior competição, que parece-me, melhor auxilia na busca do difícil ponto de equilibrio acima referido ${ }^{14}$

Se a maior abertura da competição beneficia apenas a parcela mais avantajada dos usuários da public utility ou se ela permite ser utilizada pelo entrante apenas para se assenhorear da parcela economicamente, mais interessante do mercado, sem qualquer benefício para o restante dos consumidores efetivos ou potenciais, tenho cá comigo que ela não se justifica. Afinal, a regulação de uma atividade essencial desmonopolizada deve ser, sempre, enfrentada como um todo, levando-se em conta a completude dos interesses nela enredados. Criar uma competição de cujos benefícios só vão se aproveitar os hipersuficientes em detrimento do aperfeiçoamento de obrigações de universalização de que possam se aproveitar, majoritariamente, os hiposuficientes, se coloca em afronta às premissas estruturantes da ordem constitucional brasileira.

Deveras. Privilegiar o vetor do benefício competitivo quando majoritariamente apropriado pelos consumidores hipersuficientes, em detrimento do aumento da base dos que podem usufruir de uma atividade essencial, viola tanto os princípios e objetivos fundamentais da República (cf. art. $1^{\circ}$, II e III e art. $3^{\circ}$, I, III e IV), quanto os axiomas estruturantes da Ordem Econômica (cf. art. 170, caput e incisos III e VIII).

il tuo: concorrenza e servizio universale". In "Mercato. Concorrenza, Regole". II Mulino, Anno I, n. 1, aprile 1999, p. 76.

13 Em sentido contrário, ver Eros Roberto GRAU, "A Ordem Econômica na Constituição de 1988 ", $5^{\text {a }}$ edição, São Paulo, Malheiros, 2000, p. 151 e ss.

14 Calha perfeitamente, neste ponto, o que assevera Adolfo CASTILLA: "de la teoria revisada se deduce que la regulación surgió para controlar a los monopolios y para conseguir que éstos trabajen como si existiera competencia. Si se itnroduce competencia en los sectores monopolisticos. cuál es el papel de la regulación? La contestación a esta última pergunta parece estar en que no es posible pasar del monopolio a la competencia sin una etapa de transacion. Lo normal y aconsejable será pasar a lo que se suele denominar como "competencia regulada", una situación intermedia en la que se necessita una regulación para aprender a competir y para defender a las nuevas empresas y al cliente final por encima de toda. CF. "Economia y Regulacion em las Telecomunicaciones", In Javier CREMADES (Coord.) "Derecho de las Telecomunicaciones", Madrid, 1997, La Ley Actualidad S.A., p. 886. 
Segue daí que, sem descurar da introdução da competição (em última instância mecanismo para assegurar importantes pautas constitucionais, como a livre iniciativa e a defesa do consumidor), tenho como certo que a atividade regulatória estatal, em qualquer de suas manifestações (quer setorial, quer da concorrência), não poderá desprivilegiar as metas de universalização e continuidade da fruição de um serviço público, sob pena de violar, entre outros, os princípios constitucionais da dignidade humana e a redução de desigualdades sociais e regionais.

Nem se diga que ao privilegiar a competição, mesmo que com benefícios apropriados inicialmente pelos grandes consumidores, os ganhos tendem a ser compartilhados pela sociedade pois a redução nos custos dos insumos concorre para a diminuição dos preços dos produtos de cada indústria que se utilizar da public utility como insumo. Embora este raciocínio seja consistente, em termos econômicos, não imputo-lhe força suficiente para justificar o menoscabo das pautas de universalização.

A uma, porque não há qualquer garantia de que os setores que se servem de tal insumo atuem em ambiente suficientemente competitivo para forçar a transferência dos ganhos o consumidor final.

A duas, porque, em se tratando de interesse do consumidor, mais crível é que os benefícios lhe sejam assegurados no ambiente mais fortemente regulado (com preços tarifados) do que em ambientes em que a atividade econômica é explorada em regime exclusivamente privado e a capacidade regulatória estatal não é suficiente para impedir que a economia ganha pelo adquirente do insumo (Public utility), seja integralmente transferida para o consumidor dos seus produtos e serviços. Exemplo disso é a dificuldade que o órgão regulador do sistema monetário (Bacen) encontra para ver transferida, ao consumidor final no sistema financeiro, a redução constante nas taxas de juros básicos. Isso apesar de existir razoável competição no sistema financeiro e deste segmento ser razoavelmente regulado.

$O$ fato é que não se aumenta a competição nem se universaliza o acesso a uma public utility sem que haja investimento na ampliação das redes de suporte a essa atividade. Porém, o investimento em rede para suportar a competição depende de garantias de que o cenário competitivo será assegurado e que inexistirão violações à concorrência. Já o investimento na ampliação de redes necessárias ao aumento do número dos que têm acesso exige que o investidor (em geral o incumbente) tenha garantias de que alguma vantagem competitiva equilibrará estes ônus ${ }^{15}$.

15 Em, outra oportunidade, escrevi que: "A competição procura a maior oferta do serviço aos consumidores coordenada com uma oportunidade atraente para as empresas que virão disputar este mercado. Busca garantir alguma margem de competição para aquela que já está no mercado. Para assegurar a efetiva universalização há que se estabelecer um regime de preços com limites para a cobrança deste serviço (evitando o expurgo dos usuários que já dispóe do serviço). Porém, tem que se assegurar margens de remuneração que permitam os investimentos necessários a ampliar o conjunto daqueles que disporão dos serviços (por exemplo, inversões em telefones públicos e comunitários para aqueles usuários que não têm mínimas condiçōes de remunerar a assinatura de um serviço)." (Cf. "Direito das Telecomunicações e Anatel", In "Direito Administrativo Econômico", cit., p. 308. 
Doutro bordo, este investimento há que ser articulado, evitando-se assim duplicidades de rede e, por conseqüencia, ineficiência econômica. Não é por outra razão que um dos pontos mais sensíveis nos processos de quebra de monopólios é justamente aquele que trata de compartilhamento de redes (interconexão, remuneração por uso de redes ou exploração industrial e compartilhada de infra-estruturas). Aqui também se coloca a questão do equilíbrio entre competição e universalização e continuidade.

A regulamentação do uso das redes do incumbente não deve ser tal que atenda apenas ao interesse do entrante (obrigando o incumbente a investir não para atender o beneficiário potencial da universalização, mas apenas para viabilizar a estratégia empresarial do competidor), comprometendo a universalização (em virtude quer da inversão nas prioridades de investimento, que por subtrair drasticamente receitas do incumbente, inviabilizando a geração de receitas) e ou ponto em risco a continuidade (em virtude dos problemas de segurança e confiabilidade gerados por eventual falta de critérios nesse compartilhamento).

Em suma, quando estamos diante da abertura de segmentos antes objeto de monopólios e que envolvem atividades essenciais à coletividade (mormente atividades consideradas serviços públicos), a introducão da competição (e por consequiência a utilização do aparato regulatório do direito da concorrência) deve ser condicionada por outras pautas sobretudo relevantes ${ }^{16}$. A eficiência econômica perseguida pela competição deve ser posta em cotejo com a eficácia das políticas públicas elegíveis para tal segmento. Nos quadrantes da Constituição vigente, não se põe aceitável privilegiar o ângulo da competição nos serviços públicos sem assegurar meios e condições para atendimento de metas e parâmetros de universalização e continuidade da prestação da utilidade pública. E na identificação do ponto de equilíbrio entre estas duas dimensões deve-se adotar, como chave, a identificação dos benefícios potenciais, evitando que parcelas hipersuficientes da sociedade se beneficiem em detrimento dos segmentos menos afortunados e excluídos da fruição do serviço público.

Feitas estas longuíssimas considerações gerais, é tempo de abordar as questões específicas para o devido enfoque da matéria.

No seu parecer, a Secretaria de Direito Econômico do Ministério da Justiça SDE procedeu a uma análise bastante aprofundada do processo de desestatização da distribuição de gás no Estado de São Paulo. Fê-lo, como é natural, pelo prisma específico do direito da concorrência. Nesta toada, analisando todo o segmento gás, pondera a SDE que na cadeia de produção existem atividades potencialmente competitivas (produção e comercialização) e outras que se caracterizam como monopólios naturais (transporte e distribuição).

Após expor os aspectos positivos da introdução da concorrência, expõe o parecer sua tese central: diante da peculiaridade da cadeia do gás natural, a efetiva separação

16 Neste sentido pertinente é, mais uma vez, o entendimento de Santiago Muñoz Machado no contexto espanhol: "De modo que la Ley se ha mantenido en una posición más moderada y no ha tratado de llevar la competencia hasta sus túltimas consecuencias.: In op. cit., p. 142. 
entre atividades que admitem e inadmitem a competição se colocaria como meta essencial para a adequação do segmento às premissas do direito econômico.

Nesta toada, vem a Segunda tese: a assimetria de informações e meios entre órgão regulador e o agente regulado detentor do monopólio natural (no caso ditado pela propriedade da rede de distribuição) faz relativa a capacidade de efetivo exercício da regulação comportamental. Dai porque a solução recomendada de separação jurídica das atividades, impedindo-se que a empresa monopolista participe das atividades em que se mostra viável a competição.

Outro ponto levantado no parecer se refere à fragilidade e à insuficiência da definição do conceito de distribuição adotado no setor, o que, no entender da SDE, dificulta o controle da concentração econômica e desfavorece a competição (pois obrigaria os grandes consumidores a se servirem da etapa de distribuição), reduzindo as opções de fornecimento, para estes grandes compradores, apenas à concessionária.

Destes supedâneos teóricos todos, o parecer conclui por recomendar três medidas, a saber; i) a separação jurídica entre as atividades de distribuição e comercialização; ii) a exclusão da necessidade de pagamento do by pass para os grandes consumidores que pretendam adquirir seu gás diretamente do produtor; iii) uma definição "mais racional" do que seja a distribuição. As considerações acerca de cada uma destes medidas serão feitas na seqüência. Antes cumpre fazer alguma digressão sobre aspectos gerais aduzidos no sobredito parecer.

São efetivos os ganhos trazidos pela competição. Porém, é mesmo pela peculiaridade do segmento de gás que o enfoque competitivo que pretendeu dar o parecer não se mostra o mais adequado. É que não se pode olvidar que a cadeia de produção e de transporte do segmento é extremamente concentrada nas mãos da Petrobrás.

Daí porque a segregação entre atividade de distribuição e comercialização traz subjacente o risco de concentração vertical ao invés da pretendida desconcentração. A abertura radical da competição no segmento de comercialização poderia acarretar a entrada forte da Petrobras na comercialização direta com os grandes consumidores $^{17}$. Com isso teríamos a possibilidade de, por vias transversas, chegarmos a uma concentração vertical ainda maior. E, pondo em risco a continuidade e a universalização do serviço público de distribuição, em detrimento do consumidor hiposuficiente (especialmente o residencial).

Neste ponto não é demais lembrar que o modelo de competição em implantação no setor elétrico não deve ser tomado como um paradigma puro para o setor de gás. Com efeito, se naquele segmento a liberação do setor de comercialização (mediante a figura do consumidor livre e a criação do mercado atacadista de energia) serve de eficiente cunha para introdução da competição, aqui a situação não é semelhante. Primeiro, pelo fato de que, diferentemente da geração de energia, a produção de gás natural segue sendo um monopólio de fato nas mãos de Petrobras. Segundo, porque a rede de transporte (ou transmissão) do gás não é, nem de longe, aproximada em extensão e ramificação da rede de transmissão de energia elétrica. Por fím, e a isso

17 Nunca é demais lembrar que a Petrobras já detém, na distribuição parcela significativa na própria distribuição, haja vista que a BR Distribuidora detém $15 \%$ do setor. 
voltaremos, porque as questões de segurança de rede, embora presentes nos dois setores, se mostram muito mais sensíveis no setor de gás.

Insisto que a eficiência perseguida pela linha de raciocínio adotada no parecer não deve ser tomada pelo prisma exclusivamente econômico. Mesmo que faça sentido, ao lume da racionalidade econômica, a incorporação dos benefícios da competição para o sistema econômico geral, quando estamos diante de um serviço público, há outros fatores que se deve considerar. Numa abrangência maior do princípio de eficiência (agora elevado à condição de princípio geral da Administração Pública pela EC ${ }^{\circ} 19$ ), parece-me irrazoável que o ganho econômico sobrepuje a relevância social de se assegurar a ampliação, o incremento e a democratização do acesso aos seus benefícios.

A questão de fundo, repito, não é o benefício da mais desabrida competição. É sim identificar quem deles se beneficiará. Assim, quando vemos afirmado que "a médio e longo prazo a opção pela concorrência é bem mais vantajosa uma vez que leva a serviços de melhor qualidade, por menores preços" há que se indagar quem se beneficiará deste incremento de qualidade.

Admitida a competição nos termos do cogitado pela SDE, certamente os maiores consumidores industriais conseguiram obter para si incrementos de qualidade nas redes que ser-lhes-iam disponibilizadas diretamente pelo produtor ou pelo agente transportador. Inobstante, diante da característica extremamente concentrada do consumo no segmento, lídimo imaginar que poderia restar comprometida a meta de expansão da rede, bem como seriam prejudicadas metas de substituição de medidores (Cl. Sétima, III do Contrato de Concessão), ou a meta de renovação da Rede de Ferro Fundido ( $\mathrm{Cl}$. Sétima, V do Contrato de Concessão) ou a instalação de unidades de correção de medição ( $\mathrm{Cl}$. Sétima, VII do Contrato de Concessão), todas elas relativas ao incremento de qualidade do qual se beneficiaria parcela muito maior da coletividade.

Outro ponto que, parece-me, não foi suficientemente considerado no parecer em apreço foi a amplitude do mercado de gás. Com efeito, o parecer se baseia fortemente na cadeia do gás natural. Porém, como envereda fortemente pela defesa da competição, em especial no tocante aos consumidores industriais, deve-se ter em conta que existem várias alternativas competitivas ao gás natural. Competem neste mercado diversas alternativas ao gás natural. No âmbito dos insumos energéticos há que se considerar a existência do Gás Liqüefeito de Petróleo - GLP (a granel e em botijão), Gás Natural Liqüefeito - GNL, o Gás Natural Comprimido GNC, óleo combustível ou diesel. Neste sentido, vale referir o parecer emitido pela Secretaria de Acompanhamento Econômico - SAE no mesmo processo.

Também parece necessário ressalvar que o entendimento da SDE traz grande ceticismo quanto à capacidade dos órgãos reguladores de impor medidas necessárias, tanto à preservação da competição, como à implantação das políticas públicas preconizadas para um dado setor. Tal ceticismo se revela na relativização das soluções comportadamentais e na alegação de assimetria de informações. Não compartilho de tal resignação quanto à impotência dos órgãos reguladores.

Se bem é verdade que o regulado muita vez detém informações e meios desproporcionais ao regulador, também é fato que, quando estamos diante da exploração 
de serviço público, o regulado, monopolista ou não, depende do regulador para uma série de aspectos cruciais à exploração da atividade. Primeiro, porque depende da licença (contrato de concessão ou permissão) para poder explorar o serviço. Depois, porque no caso de prestação em regime público a própria rede que lhe confere a condição de monopolista constitui bem reversível, atrelado à vigência da outorga. Também porque o agente permanece submetido ao poder sancionador do regulador, assim como dele depende para reajustamento tarifário ou para preservação das condições econômicas contratadas.

Dito de outro modo, se é verdade que na regulação econômica a cargo dos órgãos de defesa da concorrência, versante sobre atividade econômica em sentido lato, as soluções comportamentais se apresentam como de baixa eficácia (haja vista a reduzida sujeição do agente econômico ao órgão regulador), no caso de regulação setorial de serviços públicos (inobstante presente o risco gerado pela assimetria informacional) é muito mais efetivo o poder do regulador, o que não permite que simplesmente desqualifiquemos as medidas regulatórias comportamentais.

De resto, antes de adentrarmos nos três aspectos específicos do parecer, cumpre-me tecer encômios quanto ao enfoque dado à integração vertical do setor de gás na cadeia de produção de energia elétrica (no aspecto específico das termoelétricas). Efetivamente, é pertinente a preocupação no sentido de que haja um acompanhamento e um controle de toda a cadeia. Neste sentido, parece-me que tal preocupação deveria envolver não apenas a ANEEL, como recomendado pela SDE, mas envolver a ANP (dada sua competência regulatória sobre a produção e o transporte de gás natural), a CSPE (no caso de São Paulo o órgão regulador para a distribuição e a comercialização do gás), além da ANEEL (no tocante à geração de energia elétrica) e o próprio CADE (cuja função regulatória da concorrência permite servir de elemento aglutinador e sistematizador da regulacão em toda a cadeia).

Assim postas minhas considerações gerais acerca do parecer da SDE, cumpre enfrentar as três recomendações apresentadas.

A principal recomendação contida no parecer se refere à separação jurídica entre as atividades de distribuição e comercialização. Sustenta a SDE que sem isso haveria uma indesejável comunicação entre a atividade não competitiva (distribuição, no seu entender um monopólio natural) e outra, competitiva (a comercialização). Como visto, parte-se do entendimento de que a simples previsão de soluções comportamentais no contrato de concessão não seria suficiente para atingir a competitividade desejada.

De início, há que se destacar que a separação jurídica não é apanágio para todos os males dos monopólios naturais. Estudando a questão no âmbito do setor elétrico, Santiago Muñoz MACHADO obtempera que: "la separación juridica de actividades es un instrumento pero no una fórmula mágica. Quiere decir-se que, por una parte, la separación juridica no produce competencia por su sola virtud. $Y$, por otra, que la separación juridica lo que pretende es alejar al máximo la influencia recíproca de las sociedades que producen y las que distribuyen electricidad (o cualesquiera otras a las que se imponga la misma medida de separación). Sin embargo, si no se adoptan medidas sobre la propriedad, es posible que sociedades distintas sean controladas por el mismo paquete accionarial dominante (...) Cualquier otra medida 
formal y paliativa seguramente exite al sector un esfuerzo económico y de reogranización inútil porque no se llegará com la separación a ninguna parte o no se extraerán com rigor todas sus consecuencias." 18

Afora não ser a solução da separação jurídica o emplastro machadiano (o nosso, de Assis, não doutrinador da cita supra) imaginado pelo SDE, tenho comigo que ela não se mostra in casu nem imprescindivel, nem recomendável no presente momento. ${ }^{19}$ Não é imprescindivel porque, a meu ver, os mecanismos previstos nos marcos regulatórios estabelecidos pela CSPE são suficientes para evitar que a atividade competitiva de comercialização reste contaminada de modo írrito ao direito econômico pela atividade monopolizada. Não é conveniente porque a implementação, agora, dessa solução acarretaria óbices jurídicos e reflexos de custos que, certamente, terão que ser assumidos ou pelo poder concendente ou pelos usuários.

É-me convincente a argumentação contrária à separação jurídica. Afora não compactuar com o ceticismo em face das medidas comportamentais, há razões específicas que devem ser levadas em conta.

De pronto cumpre consignar que a figura da comercialização no segmento de gás foi, no Estado de São Paulo, uma criação regulatória. Deveras, a Constituição Federal (art. $25, \S 2^{\mathbf{0 2 0}}$ ) alude à competência dos Estados para explorar os serviços locais de gás canalizado. Já a Constituição Estadual (art. 122, Parágrafo Único' ${ }^{21}$ alude aos serviços de gás canalizado em seu território. Nenhum destes dois textos (fonte da classificação dos serviços de gás canalizado como serviço público) prevê a atividade de comercialização. É no Decreto $n^{\circ} 43.889 / 99$ do Governador do Estado (que aprovou o Regulamento de Concessão e Permissão da Prestação de Serviços Públicos de Distribuição de Gás Canalizado, principal marco regulatório do setor) é que vamos encontrar a definição do "comercializador" de gás 22 .

Ora, se assim é, vê-se desnudada a preocupação do regulador em criar a competição, desbastando as atividades potencialmente competitivas daquelas considera-

18 Cf. "Servicio Publico y Mercado", Vol IV, el Sistema Electrico, Madrid, Ed. Civitas, 1998, p. 169.

19 Interessante neste sentido a ponderação formulada por Calixto SALOMÃO acerca das concentraçōes verticais: "As concentrações verticais, muito ao contrário das horizontais, são motivos de continuas dúvidas e discussões doutrinárias. No estado atual da doutrina nāo existe sequer concordância a respeito da necessidade e da utilidade de qualquer tipo de controle das concentrações verticais. Soretudo aqueles mais ligados à Escola Neoclássica de Chicago, afirmam que as concentrações verticais não apresentam qualquer problema jurídico autônomo em relação às concentraçōes horizontais. $O$ raciocínio por eles desenvolvido ataca um dos argumentos centrais daqueles que vêem na concentração vertical uma potencial ameaça a sistema concorrencial. Segundo essa teoria, a concentração vertical permite ao fabricante do produto final, caso o produtor de insumos ou distribuidor com o qual se está concentrando possua relevante poder no mercado, sufocar seus concorrentes, bloqueando seu acesso às fontes de insumo ou matéria prima." (Cf. "Direito Concorrencial: as extruturas", p. 29).

20 Conforme redação dada pela Emenda Constitucional $n^{\circ} 5$.

21 Conforme redação dada pela Emenda Constitucional $\mathrm{n}^{\circ} 6$.

22 Assim: comercializador: pessoa juridica, constituida por empresa individual ou coletiva, que compra gás de terceiros, de acordo com a legislação vigente, e o revende a usuários finais livres, localizados no Estado de São Paulo." 
das "monopólio natural". Percebe-se, salvo melhor juízo, que a própria atividade competitiva já foi uma criação jurídica do regulador, apontando claramente para a preocupação deste em introduzir a competição. Ao invés de manter a atividade de venda adstrita à atividade de distribuição, fê-las separadas, apontando justamente para a possibilidade de competição.

Possibilidade esta que se tenta assegurar com mecanismos regulatórios em grande medida consentâneos com o que se tem feito em outros setores. Exemplo disso é a exigência de separação contábil apta a possibilitar a segregação de custos de cada atividade gerando, até mesmo, um cabedal de informações necessário à criação de um padrão de fiscalização ${ }^{23}$.

Não mais, não é despiciendo lembrar que nos marcos regulatórios, que nos foram submetidos, há medidas fortes para impedir a concentração vertical nos segmentos da cadeia industrial em que esta concentração mostra-se perniciosa para a competição. É o que vemos expressamente previsto no art. 10, Parágrafo único do Regulamento aprovado pelo Decreto $n^{\circ} 43.889 / 99^{24}$.

Neste quadrante vemos a proibição da concessionária fornecer a empresas a ela vinculadas volume superior a 30\% do total de sua aquisição de gás (Cláusula Décima Oitava do Contrato de Concessão); as restrições à atuação de empresas vinculadas à concessionária em termoelétricas; a obrigatoriedade de sujeição à CSPE dos contratos internos ao grupo econômico da concessionária; ou ainda as restrições às contratações privilegiadas dentro do mesmo grupo.

Imprescindível, ademais, lembrar que o contrato de concessão previu uma verdadeira "cláusula de barreira" que permite à CSPE, no acompanhamento do devir da competição e no monitoramento contra concentração econômica, adotar medidas mais radicais caso se verifique indesejável concentração vertical no segmento. É o que se verifica no disposto na Segunda Subcláusula da Cláusula Décima Oitava do instrumento, cuja simples leitura dispensa maiores aclaramentos: " $A$ concessionária deverá obedecer as limitações impostas, a qualquer tempo, pela legislação e regulamentação que estabeleçam limites para a integração vertical das atividades relacionadas com as da prestação dos serviços de distribuição de gás canalizado."

A inconveniência da solução cogitada também é certa. De certo, por envolver uma nova obrigação regulatória, ainda que juridicamente possível, ela poderá ser objeto de resistência de parte da concessionária. Inobstante entendamos possível se exigir tal separação em empresas distintas (Cf. Segunda Subcláusula da Cláusula

23 É o teor da Cláusula Décima Quarta. Oitava Subcláusula " A CONCESSIONÁRIA deverá separar as informações contábeis relativas às atividades de produção, importação, armazenamento, distribuiçāo e comercialização, bem como às demais atividades não correlatadas, de Serviços Públicos de Distribuição de Gás Canalizado, possibilitando identificar as receitas, os custos e as despesas de operaçāo".

24 Parágrafo único - Os contratos de Concessão e a regulamentação pertinente poderão conter limitações de volumes de gás canalizado a serem contratados com empresas vinculadas à concessionária, bem como as restrições societárias que caracterizem empresas a ela vinculadas e as respectivas limitações quanto à integração vertical das atividades relacionadas com as da prestação dos serviços de distribuição de gás canalizado." 
Décima Oitava do Contrato), seria incontornável o advento de novos custos. Desconsiderando aqueles custos inerentes à duplicidade de estruturas empresariais e dos assim chamados custos das transações ("transaction costs"), a segregação jurídica levaria à existência de dois sistemas de faturamento e de controles. Além disso, sobreviria um ônus tributário adicional, decorrente da duplicidade de fatos geradores.

Daí decorreria, certamente, a possibilidade de pleitos de reequilíbrio contratual em favor da concessionária. Assim, tal reequilíbrio seria assumido ou pelo consumidor (cf. art. $40, \S 1^{\circ}$ do Regulamento aprovado pelo Decreto $n^{\circ} 43.889 / 99$ ) ou pelo poder concendente caso assumisse o ônus de indenizar ou subsidiar a diferença de custos gerada pela medida (Cf. art. $9^{\circ}, \S 4^{\circ}$ da Lei $\left.n^{\circ} 8.987 / 95\right)^{25}$.

Isso parece-me suficiente para desaconselhar a adoção da medida de separação jurídica das duas atividades ou para, no mínimo, afastar a peremptoriedade com que ela se apreenta no parecer da SDE. Em uma palavra, sou de entendimento de que os mecanismos previstos na regulamentação e no contrato de concessão são suficientes para que a CSPE assegure uma adequada competição no segmento (especialmente no que toca à atividade de distribuição) e para impedir que o "monopólio natural" do segmento de distribuição contamine tal atividade competitiva.

A outra ordem de recomendações, constante do parecer da SDE e apresentado como condicionante para aprovação da operação em comento, cuida da exclusão da necessidade de pagamento do by pass para os grandes consumidores que queiram adquirir gás diretamente da rede de transporte (ligando-se ao city gate), o que envolveria também a reformulação do conceito de distribuição, tornando-o mais tímido de modo a excluir o transporte de gás em alta pressão do monopólio de distribuição.

Os elementos que contrariam a necessidade da exclusão do by pass já foram longamente expostos, em termos doutrinários, nos tópicos iniciais desta manifestação. Merecerão agora apenas uma revisitação, mais focada. Já a questão da definição da atividade de distribuição merecerá algumas considerações nóveis.

Assim como ocorreu com a divisão conceitual entre distribuição e comercialização, vista no tópico acima, os marcos regulatórios do segmento de gás no Estado de São Paulo também contemplaram medidas voltadas a romper o monopólio e a introduzir a competição. Porém, fizeram-no tendo por atenção não só o vetor da concorrência, mas também a preservação das condições ditadas pela essencialidade

25 Nos utilizamos mais uma vez das palavras de Gaspar Ariño Ortiz y Francisco Velasco: “... el concepto contable "coste"tiene una significación especial: los costes ereconocidos por la Administración a efectos de la tarifa son ingresos a efectos de la retribución de las empresas elétricas. Por ello, com el diferimiento de costes, la Administración se ha comprometido explicitamento a que todos los costes activados serán recuperados - esto es, amortizados - en el futuro, com cargo a los incrementos futuros de la tarifa. Por ello también hemos de calificar a dichas cantidades como amortizaciones aplazadas, com derechos plenos - no mera expectativa de derecho... Por todo ello, no se deben plantear dudas sobre la recuperabilidade de dichos costes en um proceso de transición hacia un modelo competitivo". "Los Costes de Transicion a la Competencia: Perspectiva Juridica" in Competencia y Sector Electrico: Un nuevo regimen juridico, Madrid, Ed. Civitas, 1998, cit. pp. 155 e 156. 
da public utility gás (ou seja, a necessidade de assegurar continuidade e universalização da prestação pelo incumbente).

Neste sentido, pode-se arrolar a previsão de acesso livre e não discriminatório pelos consumidores livres ao sistema de distribuição (Cl. Oitava, XI, do Contrato de Concessão) ou o caráter transitório da exclusividade para os consumidores industrial e termoelétrico.

Doutro bordo, os mecanismos de fiscalização e o marco tarifário constante do contrato dão-me a firme conviç̧ão que a CSPE reúne instrumentos para coibir qualquer distorção advinda da posição dominante da concessionária.

De resto, a própria decisão política de divisão do Estado em três áreas de concessão já predica uma firme disposição de criar a competição pois permite aos grandes consumidores, no seu processo de alocação de investimentos em plantas industriais, considerar preços e qualidade de serviços ofertados por estas três concessionárias.

Há fundadas razões que me levam a discordar do condicionamento da aprovação da operação à supressão da obrigatoriedade pelo pagamento do by pass físico. Tentarei expô-las topicamente.

A primeira é decorrência direta da convicção doutrinária atrás exposta. Eliminar a necessidade de pagamento pelo by pass físico, a ser praticado pelos grandes consumidores, é privilegiar desabridamente a competição descurando de que estamos diante de uma atividade econômica essencial, v.q., de um serviço publico. As informações trazidas pela consulente são veementes neste sentido. Segundo o material que me foi confiado, os consumidores industriais são responsáveis por mais de $90 \%$ dos volumes comercializados pela concessionária. Num determinado percurso de $100 \mathrm{~km}$ de rede, se apenas duas indústrias conectassem-se diretamente ao produtor ou à rede de transporte, sem pagar por esse by pass, haveria um impacto negativo de $25 \%$ da margem de distribuição dos demais consumidores.

Se o by pass não oneroso se generalizasse, teríamos um benefício apropriado por alguns poucos consumidores industriais em detrimento de outros segmentos inteiros (o residencial, por exemplo) e mesmo parcelas relevantes do segmento industrial ou comercial (os que por escala ou por distância da rede de transporte não lograssem conseguir o by pass) ${ }^{26}$.

Ora, neste contexto estaríamos indo contra as pautas principais justificadoras da privatização da exploração de uma utilidade pública. Estaríamos comprometendo tanto as metas de universalização (ampliação da transferência do consumidor potencial para o consumidor ativo) e mesmo da continuidade (pois que a redução das receitas da concessionária enseja o risco de interrupção ou redução da prestação aonde ela não mais se fizer viável ou inconveniente).

A mitigação da competição em favor da universalização tem sido diretriz constante mesmo em modelos de abertura de mercado em que se inspirou o parecer da SDE. Exemplo disso é a Diretriz da Comunidade Econômica Européia sobre o

26 Assombroso é o dado de que apenas uma termoclétria de $1000 \mathrm{Mw}$ consome $5,0 \mathrm{MMm} 3 / \mathrm{dia}$ enquanto todo o mercado residencial (repito, a totalidade dos consumidores de gás residencial para uso doméstico) representam um total de 0,2 $\mathrm{MMm} 3 /$ dia. 
assunto. Na Diretiva n ${ }^{\circ}$ 93/30/CE do Parlamento Europeu e do Conselho (22 de julho de 1998) encontramos a seguinte regra: "Art. 17, l. As empresas de gás natural podem recusar o acesso à rede com base na falta de capacidade, ou se esse acesso à rede impedir de cumprir as obrigações de serviço público a que se refere o $n^{\circ} 2$ do artigo $3^{\circ}$ que thes tenham sido cometidas ou ainda com base em sérias dificuldades econômicas ou financeiras...". A permanência e a universalização dos serviços essenciais reconhecidas como elemento suficiente para justificar e legitimar alguma mitigação nos mecanismos de livre competição.

Em remate a esse item. insisto que nada garante que os ganhos obtidos pelos grandes consumidores industriais com capacidade para efetivar o by pass revertam para os consumidores dos seus produtos ou serviços. Concorre para nossa convicção o fato de que dificilmente os consumidores industriais com capacidade para realizar o by pass são, em regra, aqueles que têm posição dominante em seus respectivos mercados, tornando improvável que venham a, sobranceiramente, transferir a seus consumidores eventuais ganhos obtidos com essa nova dimensão competitiva.

O segundo argumento que para mim leva, indesviavelmente, a negar a necessidade da recomendação da SDE sobre o by pass é o fato de que tal medida serviria como um desincentivo ao investimento na ampliação das redes. Por certo, ao se permitir que a utilização da rede da distribuidora seja desconsiderada, sem qualquer ônus, por uma parcela de seus consumidores num mercado tão oligopolizado significa, na verdade, inviabilizar as ambiciosas metas impostas pela CSPE para ampliação e capilarização da rede da concessionária.

E não se diga que, para viabilização do by pass físico, o grande consumidor interessado deverá investir na construção de redes próprias. Esse fato não traria benefícios para o sistema econômico ou para o segmento de gás pois a característica dessa rede não permite que dela se aproveite a universalidade ou mesmo parcela relevante dos consumidores de gás natural.

Outro argumento já expendido se refere ao fato de que ao se incentivar o by pass, mediante supressão de qualquer custo incorrente, pode-se estar favorecendo a concentração ao invés de quebrá-la. Isso porque não se pode desconsiderar que a cadeia do gás é extremamente concentrada nas etapas de produção e transporte nas mãos da Petrobras. Ao se admitir que os grandes consumidores vão buscar seu gás diretamente no city gate estar-se-ia dando à Petrobras uma posição ainda mais concentrada na cadeia produtiva, pois sua posição dominante certamente levaria a que ela se apropriasse de parcela do ganho decorrente do by pass da rede de distribuição.

Como pertinentemente ensinam Michele POLO e Carlo SCARPA, "La rete di transporto (ad alta pressione) rappresenta la essential facility che consente a chi sai presente nella fase produtiva a monte - ovvero chi disponga del gas - di venderlo ai clienti finali, e rappresenta quindi uno snodo del tutto cruciale in un mercato che si vuole aprire alla concorrenza. Lasciare la gestione di tale strumento essenziale nelle mani di uno dei principali concorrenti nelle altre fasi produttive significa attribuire a quest'ultimo un potenziale vantaggio sui revali. ${ }^{27}$

27 Cf. "Gas: quanta concorrenza parrerà attraverso i tubi?", In "Mercato Concorrenza Regole". Anno II, n.2, agosto 2000 , p. 364. 
Daí porque, analisando a cadeia do gás como um todo, não faz sentido desincentivar o uso da rede da distribuidora, favorecendo que a rede - também monpolizada - da transportadora sirva para atender aos grandes consumidores.

A última linha de argumentação é técnica. O segmento de gás tem uma peculiaridade. A questão das segurança no uso das redes assume caráter de suma importância. Mesmo porque, bem sabe o Conselheiro Acácio, gás explode. Como pertinentemente lembra a CSPE, as redes a serem construídas e operadas para viabilizar o by pass físico dificilmente poderiam ser fiscalizadas permanentemente. De outra banda, dificilmente lograr-se-ia submeter o proprietário destas redes ao mesmo regime de fiscalização e acompanhamento a que tem de se submeter a concessionária. "As redes se estendem em terrenos de terceiros, servidóes junto a rodovias ou áreas urbanizadas com múltiplas interferências que exigem pessoal técnico especializado, trazendo riscos à população em geral e de difícil controle pela agência reguladora".

Aceitos estes argumentos, que não me parecem inverossímeis nem tampouco irrelevantes, põe-se para mim de vez afastada a necessidade e mesmo a razoabilidade de se exigir a exclusão da necessidade de pagamento do by pass para os grandes consumidores.

A última nota necessária quanto a esse ponto diz respeito à crítica formulada à definição de distribuição. Diz a SDE que a definição aqui adotada é inadequada e que "a definição européia é bem mais razoável do que a utilizada no país, dado que os grandes consumidores de gás canalizado não necessariamente precisam utilizar-se do serviço de transporte de baixa pressão ...". Por traz dessa crítica, aparentemente conceitual, está toda uma concepção de modelo para os serviços de gás canalizado, segundo o qual deve-se permitir que o grande consumidor se ligue diretamente à rede de transporte (repita-se, monopólio natural da Petrobras).

Ocorre que, entre nós, há empecilhos técnicos que inviabilizam a adoção do critério conceitual baseado na pressão com que se dá a transmissão de gás. Isso porque há trechos da própria rede de transporte em que se encontra gás à baixa pressão. Doutro lado, há ramos da rede de distribuição em que se fazem necessárias ou convenientes pressões maiores. Daí porque parece-me tecnicamente inviável a adoção da definição européia defendida pela SDE.

Por derradeiro, há um argumento irrefutável que afasta qualquer possibilidade (ou utilidade) de revisão da definição de distribuição tal como defendida pela SDE. E a abrangência dos serviços de distribuição (ou seja, dos serviços de gás canalizado sob competência estadual conforme a Constituição Federal) não advém da definição regulamentar.

Está, sim, situado na própria Constituição estadual que, no seu art. 122, Parágrafo Único, determina caber ao Estado "explorar diretamente ou mediante concessão, na forma da lei, os serviços de gás canalizado em seu território, incluindo o fornecimento direto a partir dos gasodutos de transporte, de maneira a atender às necessidades dos setores industrial, domiciliar, comercial, automotivo e outros."

Segue daí que, mesmo que revista a definição proposta pela SDE, não se lograria atingir os objetivos perseguidos, pois a definição que exclua do âmbito da distribuição (serviço público estadual) o abastecimento de gás para o setor industrial (ou seus grandes consumidores) seria inconstitucional. 
Nada haveria, pois, a fazer sobre este ponto. A menos que se queira alterar a Constituição bandeirante.

Assim se coloca a questão. É certo que as preocupações reveladas pela SDE são, repita-se, pertinentes e razoáveis. Porém, tentei mostrar, o controle das atividades relacionadas às "public utilities" no âmbito da defesa da concorrência deverá ser feito com cautela e sob parâmetros distintos do que ocorre com s comezinhas atividades econômicas. 